Andromeda nebula. Two photographs of the aurora of January 25, 1938, were taken by Mr. D. R. Barber, who also contributed notes on its appearance to the local Press. The director, Mr. D. L. Edwards, supplies many other interesting items in his report, dealing with publications, the laboratory, the library, buildings and grounds, etc.

THE Observatory has recently issued the first of a series of bulletins, which will be published from time to time, probably averaging about one a year. These will include articles less technical in character than the usual papers which appear in the Monthly Notices of the Royal Astronomical Society, and will describe special lines of research undertaken at the Observatory. In the present number, the first paper, by Mr. D. L. Edwards, deals with the spectra of $\gamma$ Cassiopeiæ, of which the late Dr. W. J. S. Lockyer gave an account a few years ago. Considerable changes have taken place since, strong absorption lines replacing the early hazy ones, these absorption lines fading out again and new emission lines appearing. The most striking stage was when the absorption lines had completely disappeared and there remained only the spectrum composed entirely of emission lines, the Balmer series of hydrogen being the most prominent feature. Prof. F. I. Blumbach contributes a paper which contains six photographs of Comet Finsler (1937 f), taken in August, and this is followed by Mr. D. R. Barber's paper, "Note on the Spectrum of Comet Finsler (1937f)", which describes the objective prism spectrograms of this comet, secured on five favourable occasions in July and August. A useful table is given which supplies a list of the identified emission features of the cometary spectrum, together with their probable origin, wave-length and observed band limits. In the next paper, by Mr. Edwards, there is a description of a tube sensitometer made to a given specification by Messrs. Casella and Co., Ltd., who are also constructing a microphotometer for the Observatory.

\section{Popular Astronomy at Mount Wilson Observatory}

ReCentuy, the Carnegie Institution of Washington has catered in a practical way for the immense growth of public interest in astronomical research by opening a special building on Mt. Wilson to be devoted entirely to satisfying the layman's thirst for firsthand information on the many researches undertaken by the staff at Mt. Wilson and other astronomers. For many years, visitors have been privileged on one night per week to use the 60-in. telescope for visual observations of the heavenly bodies, but since the completion of the Angeles Crest highway about two years ago, the number of visitors has become a difficult problem. During 1936, it was estimated that 50,000 persons inspected the 100 -in. telescope when it was open to the public, and the total number who visited the Observatory on all occasions during that year reached the large figure of 100,000 . The main features of the building are, first, a room for the display of models and photographic transparencies and, second, a lecture-hall, capable of accommodating 270 persons, in which the general public are brought into direct and personal touch with the scientific staff of the Observatory. The Carnegie Institution and the Mt. Wilson astronomers are to be congratulated on their enlightened policy of giving to the public such unique facilities for the practical understanding of what scientific research is accomplishing in the realm of astronomy.

\section{Petrology of Igneous Rocks}

WrITING with reference to the review of Hatch and Wells' "Petrology of Igneous Rocks", which appeared in NAture of May 28, p. 952, Dr. A. K. Wells has directed attention to the second paragraph, which he believes suggests that he has been guilty of plagiarizing the scheme of classification of rocks put forward in the report of a research committee of the British Association. This was not the intention of the reviewer, who states that at no time has he entertained such an idea. He adds that considerations of space precluded mention of the fact, well known to him and to others interested, that Dr. Wells was the moving spirit of the committee in question. The main object of the review was to indicate the radical changes made in the new edition of Hatch and Wells' well-known text-book.

\section{White Fish Commission}

Tнw Minister of Agriculture and Fisheries and the Secretary of State for Scotland have appointed the following to be members of the White Fish Commission constituted under Part I of the Sea Fish Industry Act, 1938: Sir William Palin Elderton (chairman), Mr. H. G. Maurice (vice-chairman), Prof. Alexander Gray, Mr. G. Dallas, Mr. T. Darling. The Commission is charged under the Act with the functions of keeping generally under review matters relating to the white fish industry, and of advising and assisting the Ministers in regard thereto. The Secretary of the Commission is Mr. R. G. R. Wall, to whom all communications should be addressed at the Offices of the Commission, Nos. 6 and 7 Old Palace Yard, Westminster, S.W.1.

\section{Weather Forecasts by Telephone}

IN The Times of July 11, there is an account of a new enterprise on the part of the Dutch meteorological service and Dutch General Post Office. In Great Britain, anyone can get the latest official weather report over the telephone by asking for it at the Meteorological Office, but on the Hague telephone system the subscriber need only call the number 393131 and he will hear automatically the latest forecast, not only for Holland, but also for Great Britain, Belgium and North and West Germany. To this is added a statement of the distribution of high and low barometric pressure over Western Europe, and doubtless also an indication of the way in which the distribution is changing.

\section{British Empire Cancer Campaign}

ON the recommendations of its various committees, the Grand Council of the British Empire Cancer Campaign has made the following grants, totalling 